\title{
Philosophiques
}

\section{Pierre Gravel, Politiques, femmes, pouvoir - Éléments pour une théorie de l'otage (Essai sur le théâtre de Jean Racine), Montréal, VLB éd., 189 pages}

\section{Ginette Pelland}

Volume 19, numéro 1, printemps 1992

URI : https://id.erudit.org/iderudit/027179ar

DOI : https://doi.org/10.7202/027179ar

Aller au sommaire du numéro

Éditeur(s)

Société de philosophie du Québec

ISSN

0316-2923 (imprimé)

1492-1391 (numérique)

Découvrir la revue

Citer ce compte rendu

Pelland, G. (1992). Compte rendu de [Pierre Gravel, Politiques, femmes, pouvoir - Éléments pour une théorie de l'otage (Essai sur le théâtre de Jean Racine), Montréal, VLB éd., 189 pages]. Philosophiques, 19(1), 139-141.

https://doi.org/10.7202/027179ar d'utilisation que vous pouvez consulter en ligne.

https://apropos.erudit.org/fr/usagers/politique-dutilisation/ 
Pierre GRAVEL, Politiques, femmes, pouvoir-Éléments pour une théorie de l'otage (Essai sur le théâtre de Jean Racine), Montréal, VLB éd., 189 pages.

\section{par Ginette Pelland}

Le théâtre de Racine met en scène la vie au XVIIe siècle. C'est l'époque de Louix XIV, celle de René Descartes. Théâtre, politique, philosophie: chacun à sa manière, ces trois lieux du discours couvrent un champ analogue: celui de la fonction, d'un type de déploiement de l'être de l'homme obéissant aux règles d'une mécanique où la singularité spécifique de chacun s'évanouit. Au siècle de la suprématie sociale des gens de qualité, la qualité se perd. Quand Louis commence à régner, Racine écrit. Des pièces de théâtre où les personnages évoluent suivant la fonction qui les définit et commande leurs déplacements sur l'échiquier politique, amoureux. 
Dans le théâtre, politique, de Racine beaucoup de rôles importants sont féminins. Des figures de femmes interviennent pour montrer à quel point l'espace politique est celui de la représentation comme "pure structure de renvoi ". Elles agitent l'espace, le lieu du pouvoir, l'insécurisant, le renvoyant à la condition de sa mise en place, montrant la possibilité de sa chute. Quand elles n'occupent pas le lieu même du pouvoir, elles font ressortir l'influence qu'elles y exercent.

La Thébaïde présente ainsi Jocaste qui ne distingue nullement entre le corps de l'État et son corps propre, pas plus qu'elle ne statue quant à celui de ses deux fils qui doit occuper le lieu du pouvoir. C'est la fonction qui lui est départie, celle de veiller à l'oscillation de l'occupation du lieu du pouvoir, par l'un ou l'autre de ses fils, chacun en alternance. C'est ce qu'a en effet édicté la loi d'CEdipe dont Jocaste est la dépositaire, l'exécutrice testamentaire. L'analyse des pièces qui suivent la Thébaïde montrera surtout des femmes captives. Selon Gravel, on verra dans cette situation de captivité "une des conditions du désir racinien »: l'objet d'amour est d'abord captif, la déclaration d'amour n'ayant lieu qu'une fois la captivité établie. Ainsi Alexandre sera-t-il amoureux de Cléophile qui n'entend cependant pas être conquise au même titre que les nombreux territoires soumis par Alexandre. Quant à lui, ce ne serait qu'à elle qu'il pense "en courant aux combats", confondant son désir d'impérialisme politique avec celui de la maîtrise amoureuse du corps de sa captive aimée. Or en posant ses conditions, Cléophile se trouve à insécuriser cette confusion du politique et de l'amoureux. Andromaque, elle-même captive de Pyrrhus, le prendra cependant dans les filets de la fidélité aveugle qu'elle voue à son Hector. Pyrrhus perdra, politiquement, pour l'amour d'Andromaque qui mine son pouvoir. Dans Britannicus, Agrippine, mère jocastienne, manipulera à distance les ficelles du pouvoir dont elle dispose à son gré. Son fils Néron, curieusement, ne commencera de se dégager de ses machinations qu'au moment où il prendra lui-même Junie en otage.

Mais Racine peut aussi changer les rôles: ainsi dans Bajazet et Mithridate, le lieu du pouvoir est occupé par une figure féminine. Et Phèdre jouera, au lieu même du pouvoir, le rôle de la captive de son amour. Le théâtre de Racine, c'est en fait nombre de " figures habituelles du pouvoir accessibles à la pensée politique du XVIIe siècle". Selon Gravel, son génie particulier consiste à faire correspondre ses personnages à un certain nombre de fonctions neutres nécessaires au déploiement de la forme moderne de l'État. La fonction occupée dépouille l'individualité qualitative du personnage qui n'existe qu'au strict titre de son rôle à jouer au lieu du pouvoir. Louis XIV n'agissait pas autrement. Au lieu du pouvoir, il s'entourait de personnages essentiellement définis par la fonction 
qu'il leur fait occuper. À cet égard, peu importe à Louis que Colbert ne soit que le fils d'un marchand de draps de Rouen.

Au XVIIe siècle, la notion de fonction apparaît nécessaire pour comprendre la vie sociale dans son ensemble. Ainsi, par exemple, le costume de tout un chacun renseigne-t-il immédiatement sur le rang, la fonction, le rôle social de celui qui le porte. Il y aurait une "littérale disparition de l'individu" dans le costume. C'est bel et bien ce que donnerait à penser le célèbre a je vois des chapeaux et des manteaux " de Descartes qui présenterait, dans sa deuxième Méditation, ce que le XVIIe siècle donnait effectivement à voir.

Montréal 